\title{
LABOR DE LA INGENIERIA EN LAS JEFATURAS PROVINCIALES DE SANIDAD
}

La labor de profilaxis que tienda a mejorar las condiciones sanitarias de un país, a fin de disminuir sus índices generales de mortalidad y morbilidad, ha de desarrollarse en dos directrices principales, que tienen como objeto inmediato respectivo los individuos y el medio ambiente general. Todas las medidas de prevención que tienen por directriz los individuos y sus medios particulares caen dentro de las tareas sanitarias propiamente dichas, o sea aquéllas que son desarrolladas desde el punto de vista médico. En cambio, las que tienden a modificar y mejorar el ambiente general de una zona o concentración grande de individuos, forman un grupo especial dentro de las obras públicas y constituyen la denominada Ingeniería Sanitaria, desarrollándose desde ese punto de vista particular de la Ingeniería.

Así como el ingeniero sanitario debe conocer las características generales de las enfermedades que trata de combatir o extirpar con sus obras, y en especial lo concerniente a su etiología y transmisión, así el médico sanitario debe tener una noción general de aquellas obras y de los efectos que su ejecución produce en el estado sanitario general. Pero es evidente que esos conocimientos mutuos de índole genérica no significan el de las técnicas completas respectivas, y tan absurdo sería el que un ingeniero diera normas para el tratamiento del paludismo o de la fiebre tifoidea, como que un médico proyectara las obras a ejecutar para la evitación de dichas infecciones. De aquí que sea absolutamente precisa la colaboración de médicos e ingenieros para lograr un avance realmente eficaz en la dis minución de las enfermedades infecciosas, cuando pueda realizarse mediante la ejecución de obras especiales de ingeniería, al mismo tiempo que con una labor médica preventiva. Las infecciones en 532 que se da tal circunstancia son, especialmiente, las de origen hídrico 
directo o indirecto, pudiendo clasificarse en las primeras todas las de carácter intestinal $\mathrm{y}$, sin duda alguna, otras no intestinales de ttiología desconocida o dudosa-como parece haberse comprobado recientemente en la parálisis infantil medular-cuyos gérmenes también penetren en el organismo por las paredes intestinales, y en las segundas, aquéllas como el paludismo, anquilostomiasis, etc., que requieren la presencia del agua para el desarrollo de los gérmenes en su ciclo total, o para el de los insectos portadores de los parásitos.

Se deduce de aquí el carácter eminentemente hidráulico que, además del constructivo-general a toda obra pública-, tienen casj todas las obras importantes de la Ingeniería Sanitaria, y, de ello, la intima relación que tales obras han de tener con la economía gene- ral hidráulica y con las demás obras públicas de esta naturaleza.

Pero, si concretamos, se observa que las obras sanitarias principales, como son las de abastecimiento y potabilización de aguas, canalización y evacuación de aguas negras, depuración de aguas residuales, obras de protección contra contaminaciones, desecación o mejora de terrenos pantanosos, etc., caen todas dentro de la competencia municipal, según la vigente legislación española, careciendo tanto el Estado en general como las autoridades sanitarias en particular, de los necesarios medios coactivos para imponer su ejecución, aún en el caso de evidente necesidad y urgencia, cual se demuestra con lo acaecido al Decreto de 13 de agosto de 1920, en que se requería a 20 ciudades importantes para que ejecutaran las obras de saneamiento que su pésimo estado sanitario demandaba, sin que algunas de ellas lo hayan hecho todavía, a pesar de haber transcurrido veintitrés años.

De estas obras hay algunas, cual los abastecimientos de agua potable, que constituyen una necesidad casi vital, independientemente de su carácter sanitario. El estado de nuestro país en relación con tales abastecimientos es, no obstante, muy deficiente. Desde ia promulgación del Decreto de 27 de marzo de 1914 a la del de 17 de mayo de 1940, referentes ambos. a la subvención por el Estado a las obras de abastecimiento de aguas, ampliada por el segundo a las de alcantarillado y depuración de las aguas residuales, se aca gieron a los beneficios del primero poco más de 1.500 obras. En España existen actualmente 6.190 Municipios de más de 500 habitantes, muchos de los cuales contienen varios núcleos separados de más de 500 habitantes, pudiendo suponerse que excedan de 7.500 los grupos de población superior a dicha cifra. Si, a pesar de la subvención del 50 por 100 dada por la Dirección de Obras Hidráulicas 533 
v de la facilidad para el pago de otro 40 por 100 en 20 años, sólo se han acogido al citado Decreto esas 1.500 obras-en un período de veintiséis años-, se puede asegurar que alrededor de un 60 por 100 de los grupos susodichos, o sea unos 4.500 , carecen aún de un abaslecimiento de aguas en las debidas condiciones de cantidad y potabilidad, y esto tratándose, como antes dijimos, de una necesidad que en los pueblos más primitivos ha sido una preocupación constante $y$ evidente.

Como es lógico, las demás obras sanitarias, tales como alcantarillados, depuración de aguas negras, desecaciones de terrenos pan. tanosos, etc., sin los cuales los pueblos pueden vivir (y morir) según su parecer inerte y atrasado; se encuentran en un estado de abandono enormemente mayor.

No hace mucho que un corresponsal de un diario madrileño daba la noticia de que elementos oficiales ingleses denunciaban alarmados el hecho insólito de que existieran algunas granjas en Inglaterra que carecian de agua potable, y que incluso podría encontrarse algunos grupos de casas que carecían de alcantarillado, cosas ambas casi inconcebibles en aquel país. No tiene nada de extraño, pues, que en sus principales poblaciones: Londres, Liverpool, Dublín, Edimburgo, etc., sea inferior al 1 por 100.000 la mortalidad anual por fiebre tifoidea. En otros países del Norte de Europa, las obras sanitarias están tan adelantadas, que son muchas las ciudades en que la mortalidad por tifoideas es de alrededor del 1 por 100.000 , cual en Bruselas, La Haya, Bergen, Oslo, Estocolmo, Hamburgo, Berna, etc., siendo aún inferior a tal cifra en Berlín, Zurich y otras, además de las inglesas antes citadas. En cambio, nuestra mortalidad por fiebres tifoideas es unas 15 a 20 veces mayor, tanto en las capitales como en el resto del país, con unas 4.000 a 5.000 víctimas anuales. Si añadimos a éstas las víctimas de otras afecciones parasitarias evitables con obras de tipo sanitario, como son el paludismo, la anquilostomiasis, la parálisis infantil, etc., y tenemos en cuenta que el aumento anual de población en España viene a ser de 230.000 habitantes; no resultaría aventurado el pronosticar que la ejecución de todas estas obras que demanda la higiene más elemental haría aumentar en más del 15 por 100 el coeficiente de crecimiento de población en España.

Pero, aparte de esa mortalidad, ¿cómo se pueden computar los enormes perjuicios de la morbilidad correspondiente, y también evitable? ¿Cuántos sufrimientos y pérdidas se ahorraría al pueblo es534 pañol? ¿Cuántos otros fallecimientos por enfermedades atípicas, es- 
pecialmente infantiles, se suprimirian? ¿Cómo se vigorizaría la raza en ciertas regiones españolas sometidas al azote degenerativo del paludismo? El problema es tan profundo y de tal importancia, que cualquiera que sobre él medite ha de convenir forzosamente en que el Estado no puede menos de hacer un esfuerzo decidido hacia su resolución a costa de lo que sea preciso, incluso de una excesiva autonomía municipal que se ha evidenciado ineficaz para acometerle de veras. Y para ello juzgamos casi imprescindible una doble organización: Una fiscalización real de las obras sanitarias existentes, de las que se proyecten $y$ de aquellas que deben llevarse a cabo donde sean necesarias, y otro organismo que acometa por sí u obli. gue a los Municipios a acometer dichas obras higiénicamente necesarias. Sobre la forma de constitución y atribuciones de este último organismo no es ocasión de detenernos. Sólo haremos resaltar qu: caben para ello varios caminos, y que, cualquiera que de éstos se escoja, no puede perderse de vista el carácter especialmente constructivo e hidráulico que anteriormente señalamos ni su relación con las demás obras públicas de tal naturaleza, por cuya razón todo organismo de ese tipo habrá de entrar en íntimo contacto con las Delegaciones Hidráulicas existentes.

Respecto a la organización inspectora, aparte de idéntica competencia constructiva e hidráulica, deberá tener una mayor dimensión sanitaria, no cabiendo más solución práctica que la de efectuar tal fiscalización por medio de los servicios de Ingeniería Sanitaria de la Dirección General y Jefaturas Provinciales de Sanidad.

La existencia de la actual Sección de Ingeniería Sanitaria en la. Dirección General de Sanidad, cuya jefatura desempeña, con su conocida competencia, nuestro compañero don José Paz Maroto, es ya un paso fundamental para la creación de esa organización asesora, fiscalizadora e impulsadora; pero para que ésta pueda cumplir eficazmente con su cometido será menester: $10^{\circ}$ Dotar a dicha sección del personal y medios para poder inspeccionar las obras e instalaciones, así como consignar las correspondientes partidas presupuestarias. 2. Que la dependencia o Sección de Ingeniería Sanitaria, que teóricamente existe en los Institutos o Jefaturas Provinciales de Sanidad, tenga efectividad práctica, con su correspondiente consignación presupuestaria, para que los ingenieros jefes de tales Secciones puedan estudiar las necesidades de los pueblos de las provincias respectivas; aconsejar e informar a los Municipios sobre la mejor y más económica manera de resolverles; informar a la Sección de Ingenieria de la Dirección General sobre los proyectos municipa- 535 
les, estudiando sus posibilidades sobre el mismo terreno; inspeccionar las obras para verificar su construcción con arreglo a los proyectos aprobados; vigilar el funcionamiento de las instalaciones ya construídas; confeccionar las estadísticas generales de las obras sanitarias existentes y de las necesarias, así como de su eficacia y defectos, etc., etc.

El estudio de las necesidades de los pueblos en materia de obras públicas de carácter sanitario es una de las más urgentes labores, pues aquéllos, por su inercia y sentir localizado o por su desconocimiento, no se dan cuenta, muchas veces, de tales necesidades, que es preciso hacerles comprender desde fuera.

Es también de gran importancia la tarea de aconsejar e informar a los Municipios acerca de los proyectos de obras de esa naturaleza, pues es corriente que aquéllos caigan en manos de personas desaprensivas y poco preparadas, o en las de esas que se denominan casas especializadas, sin título alguno para ello, verdaderos charrlatanes o curanderos de las obras sanitarias, cuyos efectos son doblemente perjudiciales, ya que, no sólo terminan ejecutando obras inútiles $\mathrm{y}$-con frecuencia-más caras que las que el caso precisaba, sino que desprestigia además a la verdadera técnica competente con esos fracasos, en los que ésta no tiene responsabilidad alguna.

El informe sobre los proyectos, estudiando éstos en el mismo terreno, es también una labor absolutamente precisa para conucer los aciertos y desaciertos de los mismos, así como las posibles modificaciones que puedan señalárseles en bien de su mejoramiento técnico o de una mayor economía para las arcas municipales. Es indudable que este estudio sobre el terreno, al igual que la inspección de las obras y la vigilancia del funcionamiento de las instalaciones desde el punto de vista técnico, no podría hacerse en todo el país por la Jefatura Central de la Dirección General de Sanidad, pues sería materialmente imposible, debiendo hacerlo así solamente en casos muy especiales en que la índole de los problemas presentados o la divergencia de criterios o exija. En todos los demás, o sea, normalmente, habrán de ser las Secciones Provinciales las que ejecuten esos trabajos.

Toda esta labor habrá de hacerse, naiuralmente, en colaboración con los sanitarios propiamente dichos, con los laboratorios y, en especial, con el jefe provincial de Sanidad; pero habrá de existir también la colaboración precisa con las demás entidades interesadas en 536 estas cuestiones: Municipios, Delegaciones Hidráulicas, Diputacio- 
nes y demás organismos que se creen, entre los que podrá hallarse el organismo ejecutivo a que anteriormente hemos aludido.

La dificultad mayor para una organización de este tipo proviene de la escasez de técnicos y, concretamente, de los especializados realmente en estas cuestiones, escasez debida, a su vez, a la exigua cantidad de obras de tal naturaleza que se proyectan y construyen en España, en contraste con lo que sucede en otros países, en que cada una de las ramas de la Ingeniería Sanitaria (Aguas, Alcantarillados, Depuraciones, Basuras, Desecaciones, etc.) tiene asociaciones nutridas y. florecientes, con revistas especializadas de gran altura técnica y científica. En España se puede decir que casi la totalidad de los pocos técnicos especializados en esas ramas se hallan o se hallaron al servicio de Municipios de alguna categoría. La imposibilidad actual en que se encontrarían las Jefaturas de Sanidad para nombrar los jefes de sus Secciones de Ingeniería con carácter definitivo y en propiedad, de manera que constituyera su actividad única 0 , al menos, principal, obliga a acudir de momento a otros medios, no existiendo por ahora otra solución que utilizar los ingenieros especializados que estén al frente de los servicios sanitarios en ciudades de importancia, en primer lugar; a los ingenieros dedicados a estudios de esta naturaleza en las Divisiones o Delegaciones Hidráulicas, en segundo lugar, y a los ingenieros provinciales que se hayan destacado en actividades análogas, en tercer lugar. Estos nombramientos sólo serán actualmente posibles si se decreta la absoluta compatibilidad con sus cargos en los organismos respectivos mencionados, contribuyendo en sus trabajos a la Sanidad Nacional, precisamente, por su condición de ocupar tales cargos, y siendo com: pensados mediante las gratificaciones y derechos que se estipulan, ya que sería difícil exigir una labor (seguramente intensa) sin que produjera algún beneficio al que la llevare a cabo.

Se comprende fácilmente que esta solución no sería más que provisional, pues en tales condiciones no podrán dedicar los. ingenieros, con el personal auxiliar y los medios indispensables, más que una parte más o menos reducida de sus actividades a esta gran tarea general sanitaria; pero es también claro que se podría dar asi un avance importante en esa tarea y señalar el camino y sentar las bases para su futuro incremento, una vez que el número de técnicos especializados haga posible el que cada Jefatura Provincial tenga su cuadro de Ingeniería Sanitaria dedicado sólo o, al menos, preferentemente a ella.

José Marfa Gutíkrez Pajarts 